\title{
How to reduce and manage the hepatic arterial complications in living and deceased donor liver transplantation?
}

\author{
Deok-Bog Moon, Min-Jae Kim, Gil-Chun Park \\ Division of Hepatobiliary Surgery and Liver Transplantation, Department of Surgery, Asan Medical Center, University of Ulsan College of \\ Medicine, Seoul, Korea \\ Correspondence to: Deok-Bog Moon, MD. Division of Hepatobiliary Surgery and Liver Transplantation, Department of Surgery, Asan Medical Center, \\ University of Ulsan College of Medicine, 388-1 Pungnap-dong, Songpa-gu, Seoul 05505, Korea. Email: mdb1@amc.seoul.kr. \\ Comment on: Lin TS, Vishnu Prasad NR, Chen CL, et al. What happened in 133 consecutive hepatic artery reconstruction in liver transplantation in \\ 1 year? Hepatobiliary Surg Nutr 2019;8:10-8.
}

Submitted Jan 02, 2021. Accepted for publication Jan 20, 2021.

doi: $10.21037 / \mathrm{hbsn}-2021-2$

View this article at: http://dx.doi.org/10.21037/hbsn-2021-2

Hepatic artery (HA) reconstruction in liver transplantation (LT), particularly in living donor liver transplantation (LDLT) is nerve-wracking job due to the smallest and shortest vascular structures. The diameter of donor HA in Asian people is less than $3 \mathrm{~mm}$ in more than three quarters of the donors (1). After introduction of microvascular techniques for HA reconstruction in LDLT, the incidence of arterial complications has decreased significantly (2).

At Asan Medical Center (AMC), transplant surgeons by ourselves have performed HA anastomosis since 2002, and the outcome has improved compared to the previous era, corresponding result to Yan et al. (3). Once transplant surgeons are familiar to microscopic HA anastomosis, most of the hepatic artery thrombosis (HAT) are related to not anastomotic technique but quality of both recipient's and donor's HAs.

At AMC in 2019, we performed over 500 liver transplants including more than 400 LDLTs (4). Personally I participated in 182 LTs including 155 LDLTs and 27 deceased donor liver transplantations (DDLTs) from beginning to HA anastomosis (Table 1). Intraoperatively there was 11 problematic cases related to HA $(6.0 \%)$, and HAT occurred in 1 patient $(0.5 \%)$ and solved by re-do anastomosis using right gastroepiploic artery. Postoperatively HAT occurred in 5 patients $(2.7 \%)$ after LDLT, but other HA complications including bleeding from anastomosis, bleeding from non-anastomotic sites, and dissection of arterial wall were absent. Re-do HA reconstructions were successfully performed in all patients, but 1 patient died of irreversible severe graft damage from the initial HAT while waiting for DDLT.

Cautious intraoperative management of both donor's and recipient's HAs is primarily important to avoid HA complications. In the donor, preservation of sound donor's HA without intimal injury is more important than its adequate length because intimal dissection of donor HA is one of the reasons for HAT. Although short stumps of donor's HA is a big obstacle for HA anastomosis but it can be overcome when accustomed to non-rotating back-wall first technique (5). This fact can be reciprocally applied to the short stumps of recipient's HA.

In the recipient, meticulous dissection of hepatic hilum is important to avoid dissection or tearing of recipient's HAs, which might be the leading cause of HA complications. At the time of HA anastomosis, we should select HA branches with intact arterial wall. If one of the recipient's HA branch had discolored arterial wall despite good flow, which is one of the suspicious findings of HA wall damage, we had better choose another HA branch. In addition, recipient's HA branches with larger diameter compared to donor's HA is better option to keep sufficient arterial flow into the liver than size-matched or smaller recipient's HA branches. Hence, I prefer to use branch-patched recipient's HA for wider HA anastomosis when donor's HA is sizable, larger than $2.5 \mathrm{~mm}$ in diameter. In my personal experiences, twotimes larger recipient's HA compared to donor's HA is not a big deal for safe anastomosis because of the elasticity of arterial wall and application of microsurgical techniques. 
Table 1 Personal experience of HA reconstruction for liver transplantation in 2019

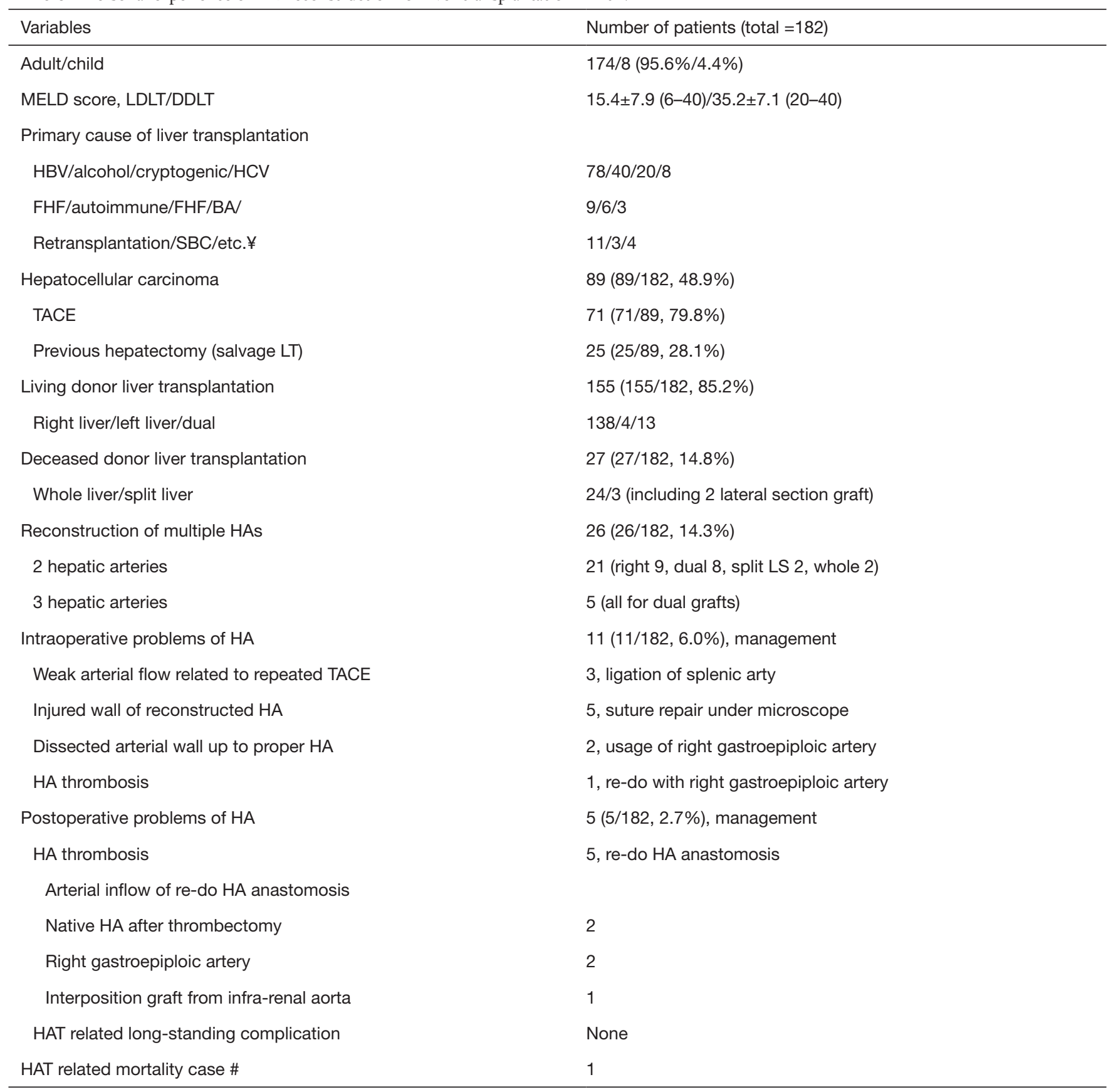

$¥$, includes Wilson’s [1], Polycystic liver disease [1], Glycogen storage disease [1], Congenital hepatic fibrosis [1]. \#, was SBC patient with history of right + caudate lobectomy with bile duct resection for bile duct cancer. At the time of LDLT, hepatic hilar structure could not be preserved due to avulsion of the hard and fibrotic hilum, and I performed portal vein reconstruction using interposition graft from superior mesenteric vein, HA reconstruction using right gastroepiploic artery, and hepaticojejunostomy. Re-do HA reconstruction was performed using cadaveric iliac artery interposition graft from infra-renal aorta. HA, hepatic artery; LT, liver transplantation; FHF, fulminant hepatic failure; SBC, secondary biliary cirrhosis; LS, lateral section; TACE, trans-arterial chemoembolization; HAT, hepatic artery thrombosis. 
When performing nonrotating back-wall first technique for HA anastomosis, recipient's HA should be larger than donor's HA to keep wide anastomosis because corner stiches at both sides of arterial wall are not possible for us to make a precise and even stiches, and using a size-matched or smaller recipient's HA for HA reconstruction are prone to anastomotic stenosis.

HA reconstruction in DDLT is usually performed using surgical loops because the diameter of HA is large enough to perform anastomosis. However, Lin et al. (6) has successfully performed HA reconstruction using microscope in DDLT. Personally I also prefer to microscopic arterial reconstruction in DDLT, particularly when obtaining the sizable recipient's HA with healthy wall is not easy under severe portal hypertension such as repeated history of upper abdominal operation including re-transplantation, salvage LT, and secondary biliary cirrhosis. Under those unfavorable situations, surgical microscope enabled us to perform sound HA reconstruction with sizable graft HA as long as we obtained recipient's HA branch with $\geq 3 \mathrm{~mm}$ in diameter and good flow. Based on unpublished AMC data about arterial reconstruction in DDLT, there is less arterial complications in microscope group $(4.7 \%$, $6 / 128)$ compared to surgical-loop group $(7.6 \%, 26 / 342)$ even though the microscope group had worse operative conditions. The possible explanations are as followings. First, microscopic anastomosis in DDLT can be performed with minimal redundancy because arterial anastomosis is usually performed using common or proper HA in the graft. As a result, redundancy related arterial complication can be reduced. Second, not only more accurate intimal approximation but also more meticulous bites of stiches can be performed, and technical problem related HA complication such as leakage or HAT might be minimized. In addition, there is a higher chance for us to detect suspicious injuries of arterial wall in both graft and recipient sides under microscopic magnification, and preemptively exact repair of injury sites might reduce the risk of bleeding from arterial wall.

Rarely but LDLT recipients should undergo HA reconstruction using non-anatomical arterial inflows when there is absence of available recipient's HA inflow. The 3 main reasons are preoperative destruction of HA from repeated trans-arterial chemoembolization, accidentally intimal dissection propagating into proper HA during hilar dissection under severe portal hypertension, postoperative HAT extension to proper HA. Lin et al. (6) described recipient's radial artery as an arterial interposition graft was used in 2 LDLT recipients to reconstruct HA under absence of available arterial inflow due to inadequate length of HA. However, most of the non-anatomical arterial anastomosis at AMC were successfully performed using right gastroepiploic artery (7). When right gastroepiploic artery was not available, we successfully used recipient's great saphenous vein from the ankle or cadaveric fresh superior mesenteric arterial branches as interposition grafts between recipient's common HA and graft's HA. In an extreme situation that all the celiac arterial system was destroyed from arterial dissection, we had to perform interposition graft from infra-renal aorta to the living graft's HA using fresh cadaveric iliac artery, and its small arterial branches was used to overcome size-discrepancy between graft's HA with small diameter and iliac artery with large diameter.

\section{Acknowledgments}

Funding: None.

\section{Footnote}

Provenance and Peer Review: This article was commissioned by the editorial office of Hepatobiliary Surgery and Nutrition. The article did not undergo external peer review.

Conflicts of Interest: All authors have completed the ICMJE uniform disclosure form (available at https://hbsn. amegroups.com/article/view/10.21037/hbsn-2021-2/coif). The authors have no conflicts of interest to declare.

Ethical Statement: The authors are accountable for all aspects of the work in ensuring that questions related to the accuracy or integrity of any part of the work are appropriately investigated and resolved.

Open Access Statement: This is an Open Access article distributed in accordance with the Creative Commons Attribution-NonCommercial-NoDerivs 4.0 International License (CC BY-NC-ND 4.0), which permits the noncommercial replication and distribution of the article with the strict proviso that no changes or edits are made and the original work is properly cited (including links to both the formal publication through the relevant DOI and the license). See: https://creativecommons.org/licenses/by-nc-nd/4.0/. 


\section{References}

1. Inomoto T, Nishizawa F, Sasaki H, et al. Experiences of 120 microsurgical reconstructions of hepatic artery in living related liver transplantation. Surgery 1996;119:20-6.

2. Mori K, Nagata I, Yamagata S, et al. The introduction of microvascular surgery to hepatic artery reconstruction in living-donor liver transplantation--its surgical advantages compared with conventional procedures. Transplantation 1992;54:263-8.

3. Yan S, Zhang QY, Yu YS, et al. Microsurgical reconstruction of hepatic artery in living donor liver transplantation: experiences and lessons. Hepatobiliary Pancreat Dis Int 2009;8:575-80.

4. Moon DB, Lee SG, Chung YK, et al. Over 500 Liver

Cite this article as: Moon DB, Kim MJ, Park GC. How to reduce and manage the hepatic arterial complications in living and deceased donor liver transplantation? HepatoBiliary Surg Nutr 2021;10(2):284-287. doi: 10.21037/hbsn-2021-2
Transplants Including More Than 400 Living-Donor Liver Transplants in 2019 at Asan Medical Center. Transplant Proc 2021;53:83-91.

5. Yamamoto Y, Sugihara T, Sasaki S, et al. Microsurgical reconstruction of the hepatic and superior mesenteric arteries using a back wall technique. J Reconstr Microsurg 1999;15:321-5.

6. Lin TS, Vishnu Prasad NR, Chen CL, et al. What happened in 133 consecutive hepatic artery reconstruction in liver transplantation in 1 year? Hepatobiliary Surg Nutr 2019;8:10-8.

7. Park GC, Moon DB, Kang SH, et al. Overcoming Hepatic Artery Thrombosis After Living Donor Liver Transplantations: An Experience from Asan Medical Center. Ann Transplant 2019;24:588-93. 